\title{
PENGEMBANGAN DATA WAREHOUSE CALL CENTER DENGAN METODOLOGI KIMBALL NINE-STEP PADA BINA SARANA INFORMATIKA
}

\author{
ADJAT SUDRADJAT \\ AMIK BSI Jakarta, adjat.ajt@bsi.ac.id
}

\begin{abstract}
As an educational institution, Bina Sarana Informatika of course requires summary of information which is comprehensive and sustainable as a support to management in doing evaluation, planning and decision-making in the field of academic services. But the information system from operational data processing today can't meet the needs, because it's only able to produce detailed reports periodically. The research studies the development of a data warehouse for Call Center on The Division of Public Information of Bina Sarana Informatika in order to explore the strategic information contained in the operational database and present them in the form of summary information which is useful as input in improving the quality of academic services. By using a nine steps kimball approach, the research produce a data warehouse which is equipped with a web-based presentation application that can be easily accessed by all stakeholders of Bina Sarana Informatika. The development of data warehouse has been able to extract operational data into strategic information summaries that are useful to Bina Sarana Informatika management as supporting in doing evaluation, planning and decision-making in the field of academic services.
\end{abstract}

Keywords : Nine Steps Kimball, Call Center, Data Warehouse, Decision Support.

\begin{abstract}
ABSTRAKSI - Sebagai sebuah institusi pendidikan, Bina Sarana Informatika tentu membutuhkan ringkasan informasi yang komprehensif dan berkesinambungan sebagai penunjang bagi manajemen dalam melakukan evaluasi, perencanaan dan pengambilan keputusan di bidang pelayanan akademik. Namun sistem informasi yang berasal dari pengolahan data operasional saat ini tidak dapat memenuhi kebutuhan tersebut, karena hanya mampu menghasilkan laporan-laporan yang bersifat detail dan periodik. Penelitian ini mengkaji pengembangan data warehouse Call Center pada Divisi Informasi Publik Bina Sarana Informatika untuk menggali informasi strategis yang terdapat pada database operasional dan menyajikannya dalam bentuk ringkasan informasi yang berguna sebagai masukan dalam usaha peningkatan kualitas pelayanan akademik. Dengan menggunakan metodologi kimball nine-step, pene litian menghasilkan sebuah data warehouse dilengkapi dengan aplikasi presentasi berbasis web yang dapat diakses dengan mudah oleh seluruh stakeholder Bina Sarana Informatika. Pengembangan data warehouse telah mampu mengekstrak data operasional menjadi ringkasan informasi strategis yang berguna bagi manajemen Bina Sarana Informatika sebagai penunjang dalam melakukan evaluasi, perencanaan dan pengambilan keputusan di bidang pelayanan akademik.
\end{abstract}

Kata Kunci : Nine Steps Kimball, Call Center, Data Warehouse, Decision Support.

\section{PENDAHULUAN}

Mobilitas kerja yang tinggi dan persaingan ketat dalam dunia usaha saat ini, harus diimbangi dengan kecepatan dan ketepatan dalam proses pengambilan keputusan strategis oleh manajemen, sehingga roda aktifitas terus berjalan on the track dalam mencapai tujuan yang telah ditetapkan. Informasi menjadi salah satu instrumen penting dalam proses pengambilan keputusan strategis. Karena itu informasi bukan hanya harus cepat, 
kredibel dan berkualitas, tetapi juga harus dapat ditampilkan dengan ringkas namun memberi gambaran yang utuh. Informasi yang diberikan saat ini juga harus dapat menjaga korelasi dan kontinuitas dengan informasi di masa lalu, sehingga lebih mudah bagi manajemen dalam membaca prediksi kejadian di masa yang akan datang dan merumuskan keputusan strategis yang cepat, tepat dan berkualitas.

Call Center merupakan salah satu unit kerja pada Divisi Informasi Publik Bina Sarana Informatika (DIP BSI) yang sudah menerapkan penggunaan sistem informasi berbasis aplikasi desktop. Namun informasi yang dihasilkan dari pengolahan data operasional tersebut masih bersifat laporan rutin. Hal ini menyebabkan manajemen masih kesulitan untuk membaca laporan tersebut secara lebih ringkas dan melihat kontinuitasnya dengan laporan yang sama pada periode sebelumnya, sehingga tidak terlihat hasil dari tindak lanjut yang sudah dilakukan terhadap aktifitas yang berkaitan dengan laporan tersebut serta sulit memprediksi situasi yang akan terjadi di masa yang akan datang. Salah satu solusi penyelesaian masalah tersebut adalah dengan mengembangkan data warehouse di lingkungan Sistem Informasi Manajemen Call Center, sehingga dapat memberikan kemudahan bagi manajemen dalam memperoleh ringkasan informasi yang berkualitas dan berkesinambungan guna menunjang proses evaluasi, perencanaan dan pengambilan keputusan strategis, khususnya dalam hal pelayanan akademik.

ini adalah :

Rumusan masalah dalam penelitian

1. Apakah stakeholder dapat memperoleh ringkasan informasi Call Center agar dapat digunakan sebagai penunjang dalam proses evaluasi, perencanaan dan pengambilan keputusan strategis bidang pelayanan akademik di Bina Sarana Informatika?

2. Apakah tersedia basis data yang dapat digunakan untuk melakukan analisa proses pengolahan data transaksi yang ada pada sistem informasi Call Center memenuhi kebutuhan stakeholder di Bina Sarana Informatika?

Tujuan penelitian adalah mengkaji mengembangkan data warehouse Call Center yang mampu menyajikan ringkasan informasi pelayanan akademik secara utuh dan berkesinambungan dari berbagai dimensi sesuai dengan user business requirement, sehingga dapat membantu manajemen Bina Sarana Informatika dalam merumuskan permasalahan, memprediksi kondisi yang akan datang, melakukan evaluasi dan perencanaan serta mengambil keputusan strategis terhadap permasalahan yang ada.

Adapun batasan pembahasan adalah fokus pada pengembangan data warehouse dalam bentuk OnLine Analytical Processing (OLAP) dilengkapi dengan Business Intelligence untuk mendukung proses pengambilan keputusan di bidang pelayanan akademik pada Call Center BSI.

Penggunaan data warehouse pada Call Center BSI dapat memberikan ringkasan informasi yang cepat, utuh dan berkesinambungan sebagai penunjang bagi manajemen dalam melakukan evaluasi dan perencanaan terhadap permasalahan tertentu di bidang pelayanan akademik, sehingga membantu manajemen dalam membuat keputusan yang tepat dan berkualitas. Manajemen BSI dapat menganalisa proses transaksi pelayanan akademik yang terjadi pada Call Center BSI secara mandiri dengan memilih bentuk laporan sesuai keinginan berdasarkan data yang tersedia pada data warehouse.

\section{KERANGKA PEMIKIRAN}

\subsection{Informasi Strategik}

Menurut Hanny Faristin (2005, p.6) informasi strategik merupakan rangkuman informasi transaksi sehari - hari guna suatu kepentingan, sehingga pihak - pihak yang akan menggunakan informasi tersebut hanya tinggal melakukan pengamatan saja, karena informasi yang ditampilkan sudah berupa ringkasan dari keseluruhan data yang dibutuhkan. Bentuk informasi strategis adalah 
ringkasan informasi baik yang berasal dari lingkungan internal maupun ekternal organisasi, dan penggunanya adalah manajemen di tingkat puncak.

Ponniah (2001, p.3) menyatakan ada beberapa karakteristik yang harus dimiliki oleh sebuah sistem informasi strategik, sebagaimana dijelaskan dalam tabel berikut ini :

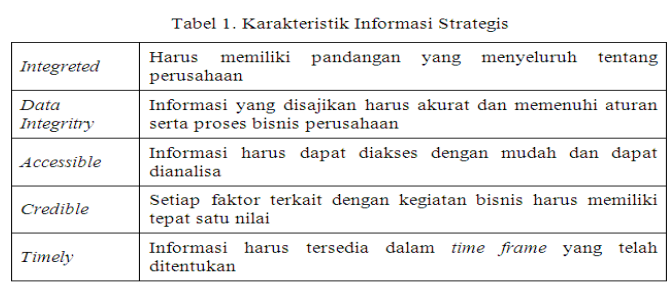

Sistem informasi yang ada seringkali kesulitan dan gagal menyediakan informasi strategik karena sumber data yang digunakan berasal dari sistem operasional sejak awal tidak dirancang untuk memenuhi kebutuhan penyediaan informasi strategik, tetapi untuk mendukung operasional kegiatan sehari-hari. Pengembangan model data warehouse menjadi solusi tepat bagi organisasi dalam menyediakan informasi strategik yang dapat digunakan oleh pimpinan puncak sebagi instrumen penunjang dalam melakukan analisa, evaluasi, perencanaan dan pengambilan keputusan strategik.

\subsection{Data Warehouse}

Menurut Nugroho (2004, p.467) Data warehouse adalah kumpulan data yang berorientasi subjek, terintegrasi, memiliki dimensi waktu serta merupakan koleksi tetap (non-volatile) yang digunakan dalam mendukung proses pengambilan oleh para manajer tingkat puncak.

Data warehouse merupakan suatu database yang memiliki struktur khusus dalam pembuatan query dan analisis. Suatu data warehouse secara tipikal berisi data yang merepresentasikan sejarah bisnis dari sebuah perusahaan. Data tersebut dikumpulkan dari berbagai aplikasi yang ada, kemudian direstrukturisasi lagi dan disimpan dalam suatu Relational Database Management System (RDBMS).

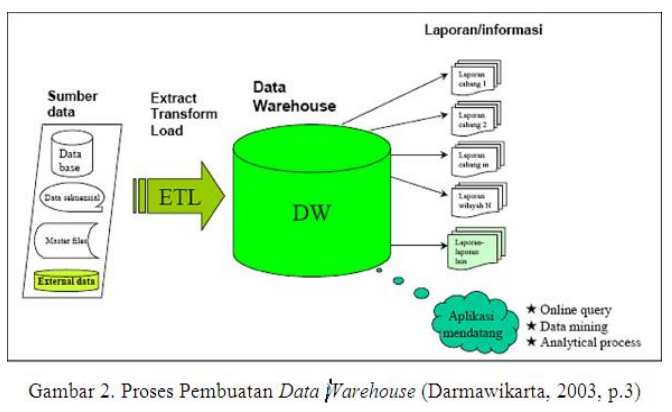

Berdasarkan gambar di atas diketahui bahwa sumber data warehouse berasal dari berbagai OnLine Transaction Processing (OLTP) database. Data yang terdapat dalam data warehouse merupakan hasil ekstraksi dari database operasional. Kemudian dengan query tertentu, data tersebut dimanfaatkan oleh Business Intelligence Application untuk menyajikan informasi strategik yang akan digunakan sebagai instrumen penunjang dalam proses evaluasi, perencanaan dan pengambilan keputusan strategik oleh pimpinan puncak.

Menurut Mallach dalam Puspitasari (2010, p.8), terdapat empat karakteristik dalam sebuah data warehouse, yaitu :

1. Subject Oriented

Suatu data warehouse dirancang untuk memenuhi kebutuhan analisis data berdasarkan subjek tertentu.

2. Integrated

Suatu data warehouse harus mampu mengintegrasikan data dari berbagai sumber sistem operasional yang beragam. Oleh karena itu sebelum data dari berbagai sumber yang berbeda ini disimpan ke dalam data warehouse maka harus menghilangkan inkosistensi data yang ada.

3. Non-volatile

Data transaksi yang sudah dimasukkan ke dalam data warehouse, tidak akan pernah diupdate atau dihapus (delete). Data yang tersimpan dalam data warehouse tidak dimaksudkan untuk aktifitas harian. Data dari sistem operasional dipindahkan ke dalam data warehouse dalam interval waktu 
tertentu disesuaikan dengan kebutuhan bisnis. Berikut ini adalah ilustrasi yang menggambarkan bahwa transaksi bisnis yang terjadi tidak mengupdate data di dalam data warehouse, namun mengupdate database sistem operasional :

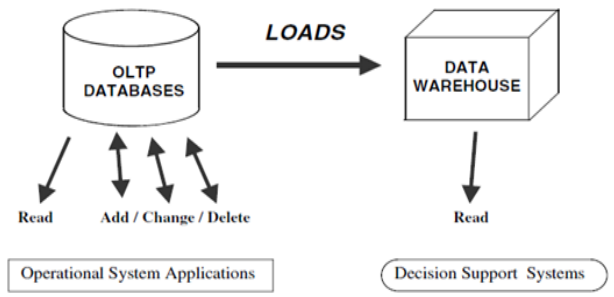

Gambar 3. Perbedaan OLTP dan data warehouse (Ponniah, 2001, p.24)

4. Time Variant

Data warehouse menyimpan sejarah (historical data). Waktu merupakan tipe atau bagian data yang sangat penting di dalam data warehouse. Di dalam data warehouse sering dis impan macam-macam waktu, seperti waktu terjadinya transaksi, waktu suatu transaksi dirubah atau waktu transaksi dibatalkan, kapan suatu transaksi bisa efektif, kapan suatu transaksi masuk ke komputer, dan kapan suatu transaksi masuk ke data warehouse. Data warehouse dikatakan bernilai bagus jika data warehouse menyimpan sejarah.

Menurut Ponniah (2001, p.28) pada sebuah data warehouse terdapat lima komponen dasar yang berfungsi sebagai buildings blocks dari data warehouse itu sendiri, antara lain :

1. Sumber Data

Data yang berada dalam data warehouse bersumber dari komponenkomponen yang meliputi : data internal organisasi, data arsip, data distribusi dari sistem OLTP.

2. Data Staging

Data yang dikumpulkan dari berbagai sumber data perlu dilakukan perubahan, konversi dan dibuat format yang sesuai dengan keperluan query dan analisis. Ada tiga fungsi yang harus dilakukan untuk memperoleh kesiapan data, yakni ekstraksi, transformasi dan pemuatan data ke dalam storage data warehouse yang disebut dengan staging area.

\section{Data Storage}

Data warehouse memiliki repositori terpisah untuk penyimpanan datanya. Repositori data dimaksudkan untuk memelihara data warehouse dimaksudkan untuk memelihara data historis dengan volume yang besar untuk kebutuhan analisis, sehingga strukturnya juga disesuaikan untuk mendukung kebutuhan analisis. Data warehouse merupakan repositori data yang read-only karena penggunaan data warehouse dalam melakukan analisa memerlukan data stabil yang mencerminkan keadaan data dalam suatu periode waktu tertentu, sehingga data yang tersimpan dalam data warehouse juga dibuat dalam keadaan sedang tidak terupdate.

4. Information Delivery

Dalam menyediakan berbagai

informasi yang berguna bagi komunitas pengguna yang beragam baik pengguna yang hanya mengandalkan report yang sudah disiapkan maupun pengguna yang mampu mengeksplorasi data untuk mendapatkan data untuk membuat query dan report sesuai kebutuhannya, komponen presentasi informasi mencakup berbagai metode penyampaian informasi. Metode ini mencakup ad hoc report yang disiapkan untuk siap pakai, query yang rumit, analis is multidimensional, analisis statistik, dan aplikasi data mining.

\section{Metadata}

Kamus atau katalog dari data yang berisi informasi mengenai data itu sendiri, misalnya struktur, informasi file, indeks, dan sebagainya. Tipe metadata dibagi menjadi tiga kategori, antara lain :
a. Operational Metadata
Merupakan metadata yang terdiri
dari semua informasi mengenai sumber data operasional, misalnya tipe data dan panjang field.
b. Extraction dan Transformation Metadata


Merupakan informasi mengenai ekstraksi data, misalnya frekuensi ekstraksi, metode dan aturan bisnis untuk ekstraksi data. Metadata ini juga terdiri dari informasi mengenai transformasi data yang terjadi di staging area.

c. End User Metadata

Navigasi data warehouse yang akan memberikan petunjuk bagi enduser untuk menemukan informasi yang dicari.

Pembangunan Data warehouse dan On-Line Analytical Processing (OLAP) dibangun berdasarkan multi dimensional data model. Model ini memberikan kemudahan bagi pimpinan puncak dalam melakukan analis is terhadap informasi yang dihasilkan dari berbagai sudut pandang. Menurut Silver dalam Supriatna (2011, p.17), terdapat dua teknik pemodelan data warehouse, yaitu :

1. Skema Bintang (Star Schema)

Skema yang mengikuti bentuk bintang, dimana terdapat satu tabel fakta (fact table) di pusat bintang dengan beberapa tabel dimensi (dimensional tables) yang mengelilinginya. Semua tabel dimensi berhubungan dengan tabel fakta. Tabel fakta memiliki beberapa key yang merupakan kunci indeks individual dalam tabel dimensi.

2. Skema Bola Salju (Snowflake Schema) Skema bola salju merupakan perluasan dari skema bintang dengan tambahan beberapa tabel dimensi yang tidak berhubungan secara langsung dengan tabel fakta. Tabel dimensi tersebut berhubungan dengan tabel dimensi yang lain.

\subsection{Business Intelligence}

Menurut Langit $(2007,1)$ Business Intelligence adalah metode untuk menyimpan dan penyajian data kunci perusahaan sehingga siapa pun di perusahaan dapat dengan cepat dan mudah meminta data yang akurat dan tepat waktu. BI yang efektif memungkinkan pengguna akhir menggunakan data untuk memahami mengapa bisnis anda mendapatkan hasil tertentu, untuk memutuskan tindakan berdasarkan data masa lalu, dan akurat memprediksi hasil di masa mendatang.

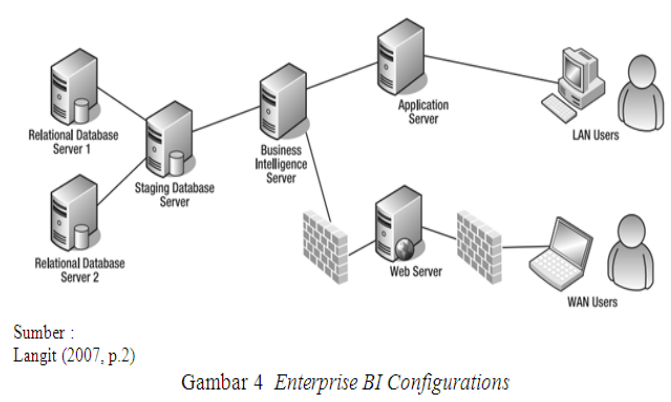

\subsection{Tinjauan Studi}

Peneliti Suprapto Darudiato (2010) meneliti sistem informasi eksekutif dalam kegiatan yang berkaitan dengan penjualan produk di Cemerlang Skin. Penelitian membahas pengembangan data warehouse yang digunakan untuk pengambilan keputusan yang berkaitan dengan penjualan produk perusahaan, namun tidak menggambarkan trend penjualan secara periodik.

Peneliti Ariana Azimah dan Yudho Giri Sucahyo (2007) meneliti SIAK Universitas Nasional, Penelitian ini menghasilkan sebuah data warehouse beserta aplikasinya berbasis web yang digunakan untuk penyampaian informasi mengenai data akademik UNAS sebagai penunjang proses pengambilan keputusan, namun tidak menjelaskan proses ETL (Extract, Transform and Loading).

Peneliti Hanny Faristin (2005) meneliti SIAK Universitas Indonesia dengan mengusulkan pembuatan data warehouse yang meliputi perancangan technical infrastructure, technical infrastructure, user defined access, ETL design dan juga Unified Modelling Language, namun penelitian ini belum sampai pada tahap implementasi.

Peneliti Diah Puspitasari (2010) meneliti SIAK Bina Sarana Informatika dengan mengusulkan pembuatan data warehouse, sehingga pihak pengambil keputusan dapat menentukan langkah yang diambil selanjutnya. Penelitian ini menje laskan proses ETL dari staging area ke database data warehouse, tetapi tidak 
dije laskan bagaimana proses pemindahan data dari sumber data ke staging area.

Peneliti Adi Supriatna (2011) meneliti dan merancang sebuah data warehouse yang menunjang sistem informasi eksekutif pada perpustakaan Bina Sarana Informatika guna memenuhi kebutuhan stakeholders akan informasi strategis guna sebagai penunjang. Pada penelitian Adi Supriatna, Proses ETL masih memerlukan banyak campur tangan database administrator, karena proses pemindahan data dari sumber data ke staging area dan dari staging area ke database data warehouse tidak berjalan secara otomatis.

\subsection{Ke rangka Pemikiran}

Berdasarkan permasalahan dan kebutuhan yang telah dijelaskan sebelumnya terbentuklah kerangka pemikiran yang menjadi dasar dari penelitian.

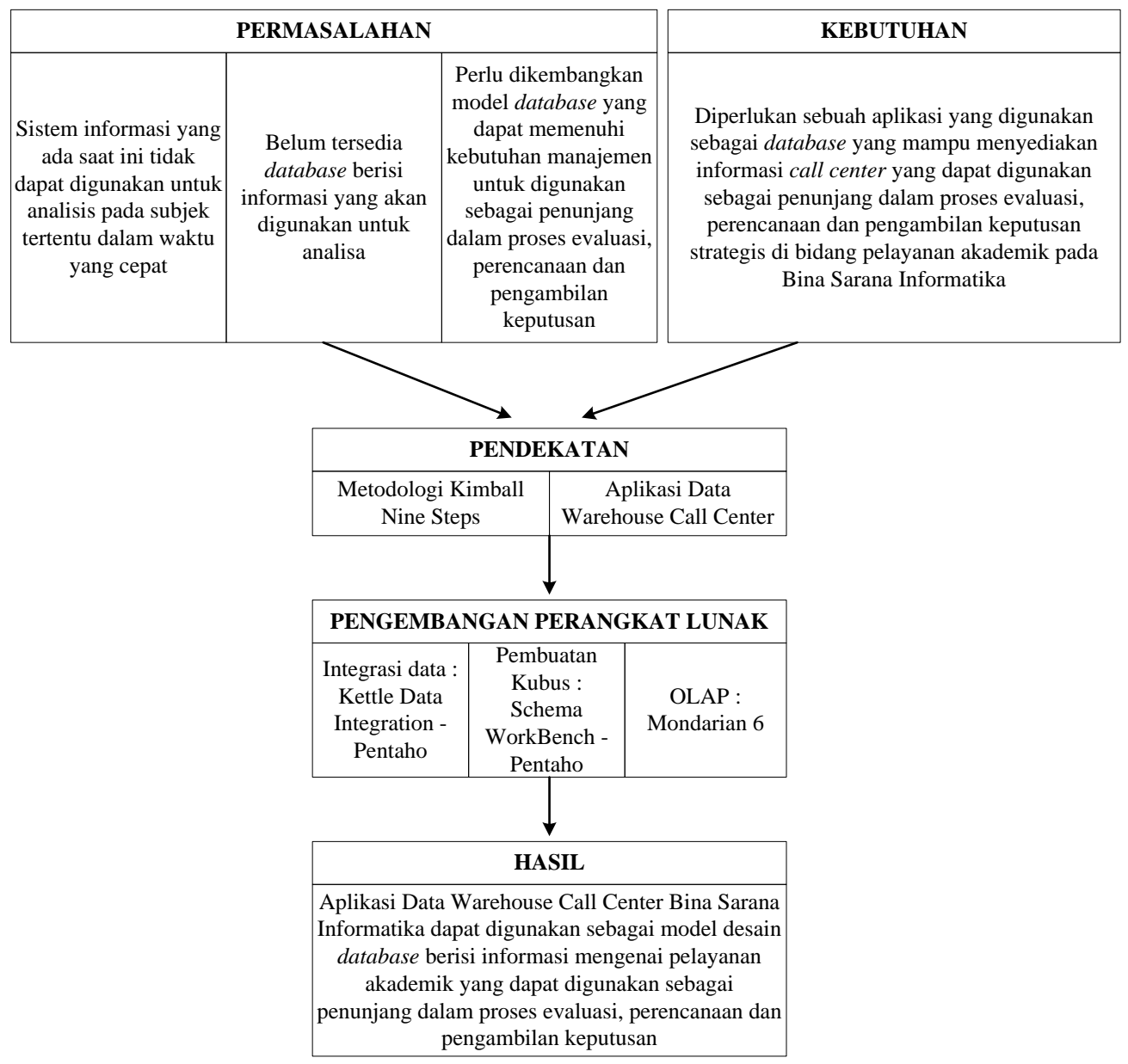

Gambar 5. Kerangka Pemikiran Perancangan Data Warehouse Call Center

\section{METODE PENELITIAN}

\subsection{Metode Pengembangan Sistem}

Pengembangan sistem dalam penelitian pengembangan data warehouse Call Center ini menggunakan pendekatan metode deskriptif kualitatif. Menurut Moh. Nazir (2002, p. 54), metode deskriptif adalah suatu metode dalam meneliti status sekelompok manusia, suatu objek, suatu set kondisi, suatu sistem pemikiran ataupun suatu kelas peristiwa pada masa sekarang. Tujuan dari penelitian deskriptif adalah untuk membuat gambaran secara sistematis, 
faktual dan akurat mengenai fakta, sifat serta hubungan antar fenomena yang diteliti. Dalam pengumpulan datanya digunakan teknik wawancara, dengan schedule questionair ataupun interview guide. Menurut Moleong (2005, p.6), metode kualitatif adalah suatu metode penelitian yang dimaksudkan untuk memahami fenomena tentang apa yang dialami oleh subjek penelitian, misalnya perilaku, persepsi, motivasi, tindakan dan lain-lain secara holistik, dan dideskripsikan dalam bentuk kata - kata dan bahasa pada suatu konteks khusus yang alamiah dengan memanfaatkan berbagai metode alamiah.

Berapa tahapan analisis data dan interpretasi yang dilakukan dalam penelitian pengembangan data warehouse Call Center dengan metode deskriptif kualitatif adalah :

1. Identifikasi subjek area

Tahapan ini dilakukan untuk mengetahui kebutuhan pengguna terhadap aplikasi yang akan dikembangkan. Kegiatan yang dilakukan adalah:

a. Observasi untuk meneliti permasalahan yang terjadi pada saat sistem berjalan dan merumuskan permasalahan dari sistem yang ada.

b. Studi pustaka untuk memahami konsep dasar teori yang mendukung penelitian.

c. Menganalisa dokumen - dokumen pada sistem yang sedang berjalan.

d. Melakukan wawancara kepada beberapa stakeholders terkait.

2. Membuat rancangan data warehouse

a. Perancangan arsitektur data warehouse

Terdiri dari Perancangan logical dan physical data warehouse. Kegiatan ini dilakukan dengan mengumpulkan data source sampai terbentuknya data warehouse.

b. Perencanaan sumber data

Sumber data diperoleh dari database Call Center yang ada di Divisi Informasi Publik dan database akademik kemahasiswaan yang ada di Biro Administrasi
Akademik \& Kemahasiswaan. Seluruh data tersebut harus melalui proses ETL pada staging area sebelum akhirnya masuk ke dalam data warehouse.

c. Pemodelan data dimensional

Penentuan model data dimensional dilakukan dengan melalui identifikasi ukuran dan fakta-fakta tabel yang akan digunakan, setelah itu menentukan dimension untuk semua informasi yang dibutuhkan manajemen untuk dijadikan sebagai parameter atau sudut pandang terhadap measure sehingga dapat mendefinisikan suatu transaksi dalam pembuatan data warehouse call center.

3. Implementasi data warehouse

a. Membuat prototype data warehouse dan aplikasi presentasinya.

1) Penyiapan hardware dan instalasi software.

2) Melakukan proses ETL (Extract, Transform and Loading)

b. Membersihkan data yang ada di sumber database.

c. Mengubah bentuk data dari sumber data yang berbeda agar mempunyai format yang sama.

d. Memasukan data yang sudah bersih dari sumber database ke dalam data warehouse

e. Menentukan bisnis area dan dimensi informasi yang akan ditampilkan.

4. Pengujian dan analisis data warehouse

a. Melakukan uji coba terhadap cara penggunaan dan manfaat dari data warehouse yang telah dibuat, apakah sudah sesuai dengan user requirement.

b. Melakukan analisa dan pendeteksian kelemahan dari data warehouse berdasarkan uji coba yang telah dilakukan.

5. Evaluasi

Pada fase ini dilakukan pengujian dengan pengguna data warehouse dan meminta saran dari pengguna untuk penyempurnaan data warehouse melalui pengisian questioner oleh pengguna. 


\subsection{Metode Perancangan Data Warehouse}

Menurut Prabhu (2006, p.34), Metodologi yang dikemukakan Ralph Kimball dalam membangun data warehouse yang disebut nine-step methodology, sembilan tahapan tersebut adalah:

Step 1 : Choose The Process.

Step 2 : Choose The Grain.

Step 3 : Identify And conform the dimensions.

Step 4 : Choose The Fact.

Step 5 : Store pre-calculations in the fact table.

Step 6 :Rounding out the dimensions table.

Step 7 : Decide The Duration of the database and periodicity of updation.

Step 8 :Track Slowly the changing dimensions.

Step 9 : Decide the query priorities and the query modes.

Semua langkah di atas diperlukan sebelum data warehouse di implementasikan, tahap selanjutnya adalah mengimplementasikan data warehouse sederhana atau data mart

Data yang digunakan dalam penelitian ini berasal dari data primer dan data sekunder. Pengumpulan data primer dilakukan dengan observasi lapangan dan wawancara. Sedangkan pengumpulan data sekunder diperoleh dari studi pustaka melalui studi literatur, tulisan ilmiah tentang data warehouse dan studi banding.

Berapa tahapan analisis data dan interpretasi yang dilakukan dalam penelitian pengembangan model data warehouse Call Center dengan metodologi Kimball Nine Steps adalah:

\section{Memilih Proses (Choosing The Process)}

Tahapan ini dilakukan untuk memperje las batasan subjek apa saja yang akan dibuat dalam data warehouse, sehingga mampu memberikan jawaban dari kebutuhan manajemen terhadap ringkasan informasi call center, sehingga dapat membantu manajemen dalam merumuskan permsalahan, memprediksi kondisi yang akan datang, melakukan evaluasi dan perencanaan, serta mengambil keputusan strategis terhadap permasalahan yang ada.

Adapun proses yang dipilih sebagai berikut : proses pengolahan data telpon masuk dari mahasiswa, proses pengolahan data telpon masuk dari dosen, proses pengolahan data telpon masuk dari cabang, proses pengolahan data telpon masuk dari pihak umum, proses pengolahan data telpon keluar untuk mahasiswa, proses pengolahan data telpon keluar untuk dosen, proses pengolahan data telpon keluar untuk cabang dan proses pengolahan data telpon keluar untuk pihak umum.

\section{Memilih Grain (Choosing The Grain)}

Grain adalah calon fakta yang akan dianalisis. Pemilihan grain dimaksudkan untuk memutuskan record apa saja yang akan ditampilkan dari tabel fakta dalam data warehouse.

Berdasarkan subjek yang dipilih pada tahap pemilihan proses (choosing the process), maka tahapan selanjutnya memilih elemen data untuk menciptakan tabel fakta. Grain yang dipilih dalam perancangan data warehouse call center yaitu : in_cabang (telpon masuk dari cabang), in_dosen (telpon masuk dari dosen), in_mhs (telpon masuk dari mahasiswa), incoming (transaksi telpon masuk), out_cabang (telpon keluar untuk cabang), out_dosen (telpon keluar untuk dosen), out_mhs (telpon keluar untuk mahasiswa), out_umum (telpon keluar untuk umum) dan outgoing (transaksi telpon keluar).

\section{Identifikasi dan Penyesuaian Dimensi (Identifyng and conforming the dimension)}

Kegiatan yang dilakukan pada tahapan ini adalah membangun satu set dimensi untuk mengatur konteks pertanyaan apa saja yang nantinya akan diajukan tentang fakta-fakta yang ada dalam tabel fakta, kemudian menentukan tabel dimensi apa saja yang harus ada dan 
membuat data mart yang cukup jelas untuk dipahami dan digunakan.

\section{Memilih Fakta (Choosing the Facts)} Pada tahapan ini dilakukan penentuan fakta mana saja yang dapat digunakan dalam data mart. Semua fakta harus diterjemahkan dalam bentuk elemen data, sesuai dengan grain yang telah ditentukan sebelumnya. Setiap fakta harus memiliki data yang dapat diagregasikan, agar dapat ditampilkan dalam bentuk tabel atau grafik.

Fakta yang terdapat dalam pengembangan data warehouse Call Center adalah telpon masuk dari mahasiswa, telpon masuk dari dosen, telpon masuk dari cabang, telpon masuk dari pihak umum, telpon keluar untuk mahasiswa, telpon keluar untuk dosen, telpon keluar untuk cabang dan telpon keluar untuk pihak umum.

\section{Menyimpan Pre-Calculation Pada Tabel Fakta (Storing Pre-calculation in the Fact Table)}

Pada tahapan ini, seluruh fakta yang telah dipilih, selanjutnya harus dikaji ulang satu per satu, agar dapat diketahui apakah ada kemungkinan untuk dilakukan pra-perhitungan. Perhitungan awal dari tabel fakta dalam pengembangan data warehouse Call Center adalah jumlah telpon secara keseluruhan baik dari kampus cabang, mahasiswa, dosen maupun pihak umum, jumlah telpon keluar secara keseluruhan baik untuk kampus cabang, mahasiswa, dosen, maupun pihak umum. Data keperluan apa saja yang sering ditanyakan oleh kampus cabang, mahasiswa, dosen, maupun pihak umum, pihak internal mana saja yang sering dihubungi oleh kampus cabang, mahasiswa, dosen, maupun pihak umum, analisa terhadap permasalahan apa saja yang sering ditanyakan oleh kampus cabang, mahasiswa, dosen dan pihak luar kepada bagian Call Center.

\section{Melengkapi Tabel Dimensi (Rounding Out the Dimension Table )}

Pada tahapan ini, kegiatan yang dilakukan adalah mengembalikan fakta yang dipilih ke dalam tabel dimensi. Teks pada tabel dimensi harus mendukung permintaan intuitif dan mudah dipahami oleh pengguna. Adapun tabel dimensi yang akan digunakan sebagai berikut : akademi, cabang, dosen, internal, jurusan, kategori, kategori_masuk, kategori_tujuan, program, status, dan tahun.

\section{Memilih Durasi dari Basis Data (Choosing the Duration of the Database) \\ Pemilihan durasi data histori yang} dimiliki oleh Call Center dapat dilakukan sesuai dengan kebuuhan informasi dari pihak stakeholder. Pada umumnya, semakin banyak data operasional yang diringkas ke dalam data warehouse, maka akan semakin lengkap pula informasi yang bisa dihasilkan. Hal penting lainya adalah perlu diperhatikan pula tingkat akurasi yang dimiliki oleh data operasional dengan isi dan format yang ada pada data warehouse, agar data yang dipindahkan merupakan data yang benarbenar relevan dan sangat bermanfaat. Bagian Call Center dapat melakukan proses perhitugan durasi database setiap enam bulan sekali.

\section{Melacak Perubahan Dari Dimensi Secara Perlahan (Tracking Slowly Changing Dimensions) \\ Pendeskripsian data yang tepat} pada tabel dimensi harus dapat digunakan dengan data operasional yang berjalan. Untuk mengamati perubahan data pada pada tabel dimensi dapat dilakukan dengan tiga cara yaitu mengganti secara langsung pada tabel dimensi, membentuk record baru untuk setiap perubahan baru dan perubahan data yang membentuk kolom baru yang berbeda. Untuk implementasi data warehouse Call Center, maka dipilih cara kedua yaitu jika ada perubahan data, maka akan dibentuk record baru pada tabel dimensi. Data baru tersebut akan dimasukkan sebagai record baru tetapi record yang lama akan tetap 
ada, ini dilakukan agar semua proses yang terjadi dalam basis data dapat ditelusuri.

\section{Memutuskan Prioritas dan Model Query (Deciding the Query priorities and the Query Mode) \\ Pada tahapan ini, proses Extract,} Transform and Load (ETL) dilakukan. Adapun periodenya disesuaikan dengan kebutuhan informasi dari pihak manajemen BSI. Pada umumnya proses ini dapat dijalankan secara otomatis melalui fasilitas Data Transformation Services (DTS) yang dimiliki oleh database engine dari basis data operasional sistem informasi Call Center ke data warehouse Call Center. Jika fasilitas ini tidak tersedia, maka proses pemindahan data bisa dilakukan oleh pihak BTI secara manual dan otomatis (Terjadwal).

\section{HASIL PENELITIAN PEMB AHASAN}

\subsection{Identifikasi Subjek Area}

Dalam pengembangkan data warehouse perlu diperhatikan hal-hal yang menjadi permasalahan yang dihadapi dan kebutuhan mendasar dari pengguna yang akan memanfaatkan infromasi strategik yang dihasilkan dari data warehouse. Inilah yang akan menjadi subjek area pembahasan dan pembangunan aplikasi data warehouse.

\subsubsection{Observasi Permasalahan}

Berdasarkan hasil observasi ditemukan permasalahan pada sistem informasi yang ada saat ini, yaitu laporan rutin dan periodik yang berasal dari database operasional belum bisa memenuhi kebutuhan akan informasi yang ringkas, komprehensif dan berkesinambungan dengan laporan yang sudah disampaikan pada periode yang lalu. Sehingga laporan tersebut harus diolah kembali jika pimpinan puncak bermaksud melakukan analisa terhadap informasi yang telah diberikan.
Dari hasil analisa yang dilakukan, terdapat kebutuhan fungsional yang harus dipenuhi antara lain :

1. Data Warehouse harus mampu melakukan analisa terhadap data telpon masuk (incoming) yang meliputi analisa pihak mana saja yang sering menelpon Call Center BSI (Cabang BSI, Mahasiswa, Dosen, Umum), kepada siapa seringnya telpon yang masuk tersebut ditujukan (pihak internal BSI), untuk keperluan apa seringnya pihak luar menelpon Call Center BSI, dan mengelompokkan data telpon masuk tersebut berdasarkan kategori tertentu dan dalam periode tertentu.

2. Data Warehouse harus mampu melakukan analisa terhadap data telpon keluar (outgoing) yang meliputi analisa siapa pihak internal sering menelpon keluar, kepada siapa telpon keluar tersebut ditujukan (Cabang BSI, Mahasiswa, Dosen, Umum), untuk keperluan apa seringnya telpon keluar tersebut dilakukan, dan mengelompokan data telpon keluar tersebut berdasarkan kategori tertentu dan dalam periode tertentu.

Dari hasil analisa yang dilakukan juga, terdapat kebutuhan non fungsional yang harus dipenuhi, antara lain :

1. Pengguna yang diizinkan mengakses informasi strategik dalam data warehouse hanya yang mempunyai akun user dan password saja.

2. Informasi strategik dalam data warehouse dapat diakses dimana saja, namun tetap melalui jaringan institusi.

3. Waktu respon maksimum untuk setiap permintaan laporan atau melihat $O L A P$ adalah 30 detik.

4. Jika proses ETL terjadi kegagalan karena ada masalah di sumber data, maka data yang ada dalam data warehouse tidak boleh rusak.

\subsubsection{Studi Pustaka}

Berdasarkan permasalahan yang terjadi pada sistem informasi pelayanan akademik (Call Center) dan kebutuhan pimpinan puncak sebagai pengguna, 
penulis melakukan studi pustaka dengan mempelajari berbagai litaretur yang berkaitan dengan usaha penulis dalam memberikan solusi terhadap permasalahan dan kebutuhan - kebutuhan tersebut.

\subsubsection{Analisa Dokumen}

Penulis melakukan analisa terhadap aplikasi sistem informasi pelayanan akademik (Call Center) serta dokumendokumen laporan yang dikeluarkan darinya guna mengetahui bentuk laporan transaksional yang sudah ada sebagai bahan masukan bagi penulis dalam merancang data warehouse Call Center.

\subsubsection{Wawancara}

Penulis melakukan wawancara dengan bagian-bagian terkait seperti Divisi Informasi Publik, Call Center, Biro Administrasi Akademik dan Biro teknologi Informasi, guna mengetahui detail bisnis proses yang berjalan di sistem informasi pelayanan akademik (Call Center), sehingga penulis memperoleh gambaran yang jelas database dan tabel apa saja yang akan diambil sebagai sumber data bagi data warehouse Call Center.

\subsection{Perancangan Data Warehouse}

Kegiatan-kegiatan yang dilakukan dalam perancangan data warehouse, antara lain :

\section{a. Perancangan Arsitektur Data}

Warehouse

Pada perancangan data warehouse ini sumber data yang dipakai adalah data operasional call center yang ada di Divisi Informasi Publik (DIP) dan data operasional akademik yang ada di Biro Administrasi Akademik dan Kemahasiswaan (BAAK) yang biasanya dipakai untuk menyimpan data harian dari sistem informasi Call Center dan BAAK yang sudah digunakan selama ini.

Berikut adalah rancangan arsitektur logical dan arsitektur physical data warehouse :

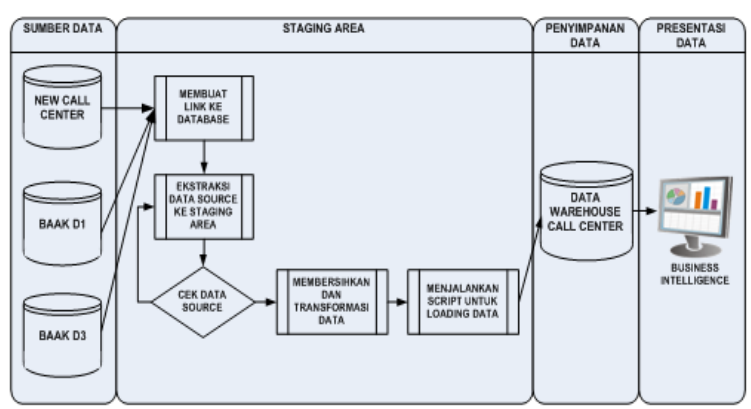

Gambar 6. Rancangan Arsitektur Logik Data Warehouse Call Center

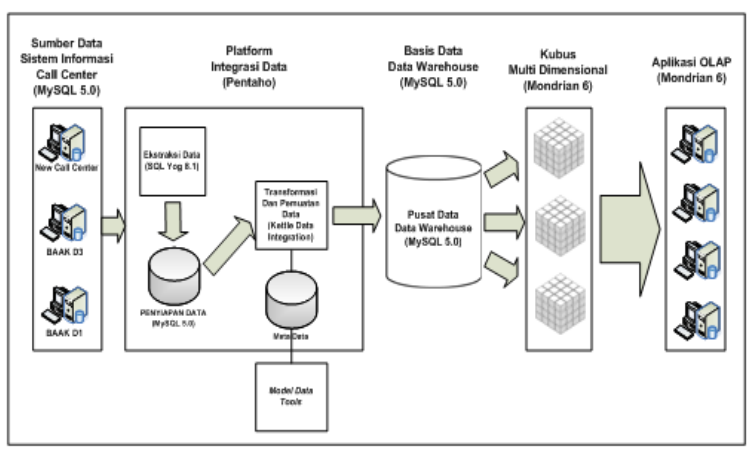

Gambar 7. Rancangan Arsitektur Fisik Data Warehouse Call Center

Di dalam perancangan data warehouse ini, user mengakses data warehouse melalui server aplikasi. Data warehouse dan server aplikasi direncanakan berada pada mesin yang sama. Database sumber dan data warehouse menggunakan RDBMS Mysql Server 5.0.

Data yang akan digunakan untuk analisis didapat dari database operasional Call Center dan BAAK. Pada data tersebut dilakukan proses ekstraksi, pembersihan, transformasi dan pemuatan data untuk dipindahkan ke dalam database data warehouse. Data yang telah dipindahkan ke dalam basis data data warehouse dirancang beberapa kubus yang akan digunakan untuk analisis data call center berdasarkan kubus-kubus yang terbentuk. Pimpinan dapat melakukan analisis terhadap informasi dari berbagai dimensi yang berbeda-beda. Untuk memudahkan melakukan analisis dibangun sebuah aplikasi OLAP dengan menggunakan Tools Mondrian 6.

b. Perencanaan Sumber Data Warehouse Dalam menunjang pelaksanaan kegiatan pelayanan akademis, BSI 
telah mengembangkan aplikasi Call Center untuk mencatat semua informasi telpon masuk dan telpon keluar, serta aplikasi BAAK untuk bidang akademik kemahasiswaan. Sumber data yang akan digunakan untuk warehouse adalah data yang diperoleh dari data operasional Call Center dan BAAK D3 dan BAAK D1, tidak semua tabel yang ada pada database - database tersebut digunakan sebagai sumber data warehouse.

c. Pemodelan Data Dimensional

Skema yang digunakan untuk pemodelan adalah star schema/skema bintang yang terdapat satu tabel fakta

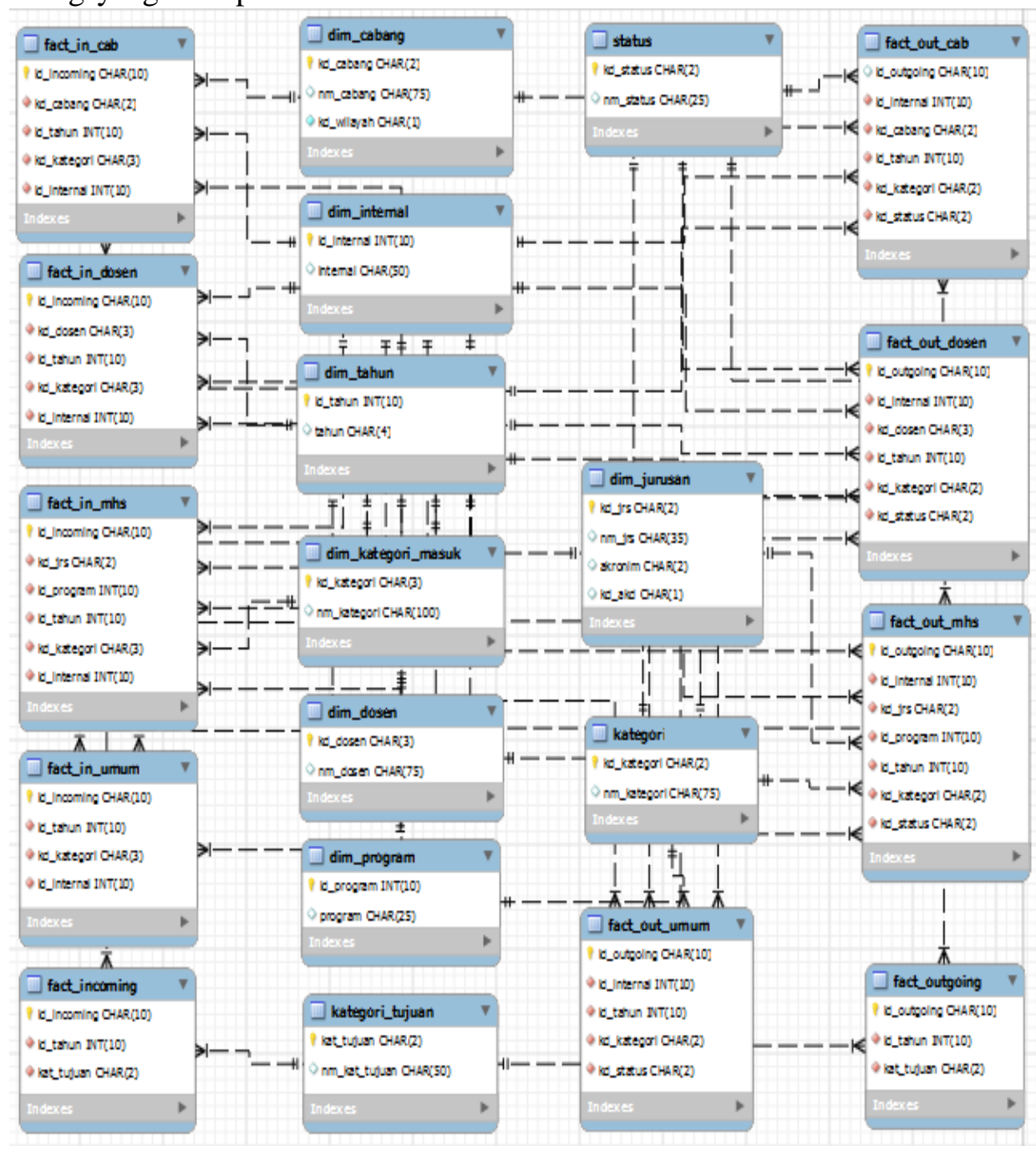

Gambar 8. Diagram ERD Data Warehouse Call Center

4.3. Implementasi Data Ware house

4.3.1. Penyiapan Hardware dan Instalasi Software dan beberapa tabel dimensi. Alasan penggunaan skema bintang ini adalah proses query lebih ringan dan memudahkan penjelajahan terhadap data dimensinya, selain itu tabel dimensinya tidak memerlukan tabel sub dimensi karena tabel dimensinya tidak mengandung ringkasan atau tidak memiliki perbedaan tingkat urutan.

Berikut ini merupakan gambar Entity Relationship Diagram (ERD) pada data warehouse call center. 
aplikasi presentasi data warehouse call center :

1. Hardware : Processor Intel ${ }^{\circledR}$ Core ${ }^{\mathrm{TM}} 2$ Duo CPU T7500 @ 2.2 Ghz, Memory 3 GB dan Harddisk 160 GB.

2. Software : Microsoft Windows 7, MySQL 5.0, SQL Yog Enterprise 8.6, MySQL Workbench 5.2 CE, Pentaho Data Integration 4.1.0, Pentaho Schema Workbench 3.2.1.13885, Pentaho Mondrian 3.2.1.13885, Apache Tomcat 7.0.6, Photoshop 6.0, Dreamweaver 8, Google Chrome 20.0.1096.1

\subsubsection{Membuat Prototype Data Warehouse dan Aplikasi Presentasinya \\ Pembuatan prototype data} warehouse dimaksudkan untuk mengetahui sejauh mana kesesuaian antara kebutuhan user dan Data warehouse yang dibuat. Prototype ini akan dijadikan sebagai gambaran umum untuk merepresentasikan model data warehouse yang dibuat. Kegiatan itu meliputi :

a. Penyediaan Informasi

Pembangunan data warehouse kebutuhan informasi yang cepat, tepat dan akurat, sehingga kegiatan evaluasi, perencanaan dan pengambilan keputusan di bidang pelayanan akademik dapat berjalan dengan baik.

b. Presentasi Data Warehouse

Pemanfaatan tools dalam presentasi data perlu dipertimbangkan beberapa hal meliputi fitur yang ada, biaya saat melakukan development dan maintainance setelah data warehouse beroperasi.

Untuk presentasi data, platform database yang digunakan untuk data warehouse ini adalah MySQL 5.0, sedangkan tools yang digunakan untuk menyampaikan informasi kepada pengguna adalah tools yang dapat berintegrasi dengan MySQL sebagai platform database data warehouse, yaitu Mondrian.

Selain Mondrian, tools yang digunakan untuk menyampaikan informasi kepada pengguna adalah JPivot yang merupakan JSP yang dapat menampilkan OLAP table dan chart. JPivot mempunyai kemampuan navigasi OLAP seperti drill down, Slice and Dice.

Sedangkan untuk media yang digunakan untuk mempresentasikan data adalah berupa web browser (Firefox, Opera, Chrome, dll) yang aplikasinya berbasis web dengan bahasa pemrograman java.

Berikut ini adalah contoh laporan In Cabang Per Tahun.

Tabel 2. Tabel Jumlah In Cabang PerTahun

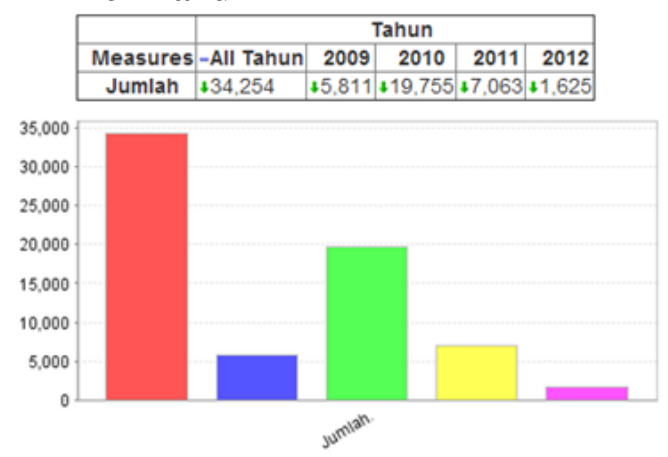

Tabel di atas merupakan laporan jumlah in cabang (telpon masuk dari cabang) yang dapat dilihat berdasarkan parameter tahun. Tabel tersebut dihasilkan dari kubus fact_in_cabang yang di dalamnya terdapat dimensi tahun sebagai parameter.

\subsubsection{Proses Extract, Transform and Loading Data}

Proses penting dalam pengoperasian data warehouse Call Center BSI adalah proses Extraction, Transformation and Loading. Proses ETL data Call Center dieksekusi dengan menggunakan program aplikasi berbasis Java yang disebut "Kettle Data Integration". Berikut ini adalah contoh rancangan integrasi data dan proses ETL pada Call Center BSI dalam mempopulasikan Tabel fact_in_cab 


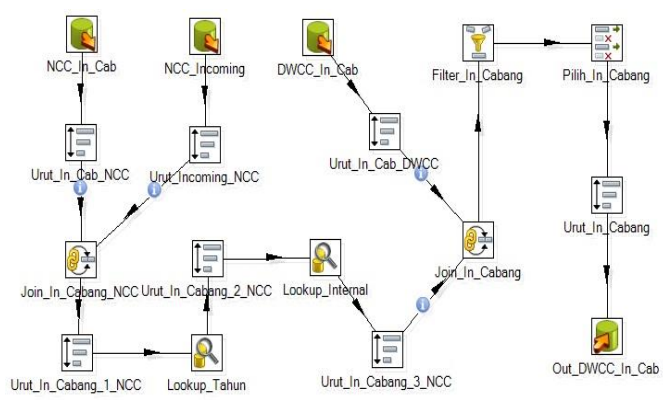

Gambar 8. Proses populasi tabel fact_in_cab

Pada tabel fact_in_cab ditentukan elemen data yang akan menjadi dimensi yaitu : cabang, tahun, kategori masuk dan internal.

\subsection{Pengujian dan Analisis Data Warehouse}

Proses uji coba awal terhadap data warehouse dimulai dengan pengujian dari data warehouse itu sendiri dan prototype interface dari data warehouse.

1. Pengujian data dari data warehouse.

Pengujian dilakukan dengan menggunakan query dari data call center dan akademik terhadap data yang ada di database data warehouse menggunakan perangkat SQL Yog Enterprise dengan memperhatikan mapping kolom dan tabel yang tersedia.

Berikut adalah data incoming dalam database new_call_center yang merupakan sumber data (OLTP) dan data fact_incoming dalam database dw_call_center yang menjadi data warehouse (OLAP) sebagaimana gambar di bawah ini :

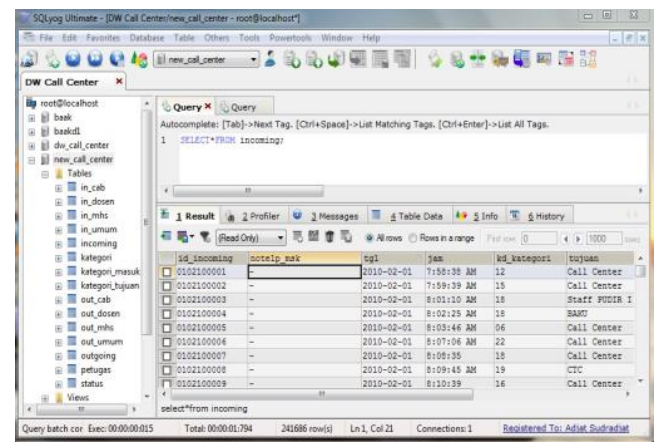

Gambar 9. Tampilan Data incoming dengan SQL Yog Enterprise

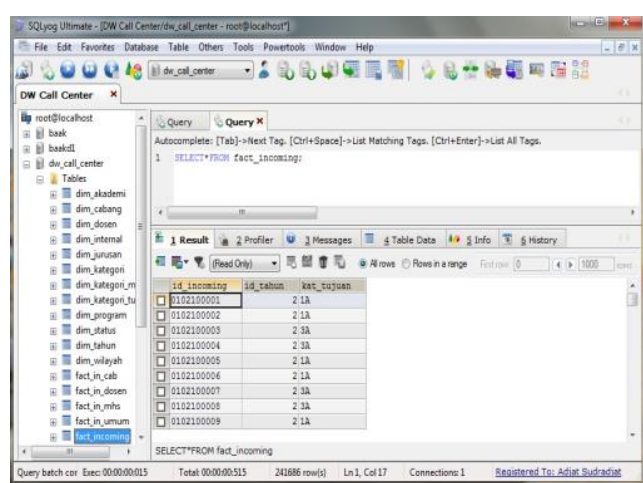

Gambar 10. Tampilan Data fact_incoming dengan SQL Yog Enterprise.

Berdasarkan dari hasil ujicoba dengan perangkat SQL Yog Enterprise menunjukan adanya konsistensi, karena tidak terdapat perbedaan antara data sumber (OLTP) dengan data warehouse (OLAP).

2. Pengujian prototype interface data warehouse oleh pejabat di bidang pelayanan akademik yang akan menjadi pengguna data warehouse. Pada pengujian ini diundang responden yang merupakan ahli di bidang masing - masing yang diharapkan mampu memberikan validasi ahli (Expert Judgement) terhadap data warehouse call center.

Hal - hal yang digunakan sebagai acuan dalam uji coba prototype interface adalah :

a. Tingkat user friendly dalam penggunaan aplikasi.

b. Tingkat kemudahan menjalankan aplikasi

c. Tingkat respon yang diberikan aplikasi dalam setiap action dari user.

d. Kemampuan data warehouse dalam merepresentasikan informasi yang dibutuhkan dalam pengambilan keputusan strategik, seperti :

1) Informasi tentang telpon masuk dan telpon keluar dari dan untuk berbagai pihak yang mendukung proses evaluasi dan perencanaan pelayanan akademik tentang layanan apa saja yang perlu dimaksimalkan oleh manajemen 
untuk cabang BSI, mahasiswa, dosen maupun pihak umum di luar civitas akademik.

2) Informasi tentang trend pelayanan akademik kepada cabang - cabang BSI, mahasiswa, dosen maupun pihak umum di luar civitas akademik berdasarkan keperluan mereka menelpon atau ditelpon oleh Call Center.

e. Kemudahan yang disediakan oleh data warehouse dalam membantu untuk menganalisa data dari berbagai sudut pandang.

f. Kemampuan aplikasi untuk menganalisa data sebagai bahan pertimbangan dalam proses pengambilan keputusan strategik.

g. Kemampuan data warehouse dalam menghasilkan informasi yang dapat mewakili kelengkapan data dan mewakili kebutuhan informasi lembaga, khususnya di bidang pelayanan akademik.

\subsection{Evaluasi}

Dari hasil evaluasi awal ditemukan beberapa kelemahan dari data warehouse dan interface prototype, antara lain :

1. Belum terdefinisikan dengan baik pihak umum yang menelpon atau yang ditelpon, karena desain database operasional belum terlalu spesifik dan user yang menggunakan aplikasi operasional Call Center belum sepenuhnya memasukan data operasional dengan benar dan baik sesuai yang diharapkan sistem informasi call center.

2. Dalam Proses ETL dari data sumber ke data warehouse, masih membutuhkan bantuan database administrator untuk merapikan data pada field - field tertentu akibat tidak cermat atau tidak konsistennya user pengguna aplikasi operasional Call Center dalam memasukan data.

3. Dengan waktu penelitian yang terbatas, data warehouse belum mampu membuat prediksi informasi apa yang dibutuhkan selanjutnya dalam bidang pelayanan akademik kepada civitas akademik maupun pihak luar.

\subsection{Perubahan Yang Diharapkan}

Dengan penggunaan data warehouse, proses pembuatan laporan yang komprehensif dan berkesinambungan tentang informasi pelayanan akademik dapat dilakukan dengan cepat dan efektif, karena tidak diperlukan lagi pembuatan query baru atau mengolahnya secara manual dengan aplikasi spreadsheet.

Data warehouse memungkinkan pembuatan laporan dari berbagai dimensi yang ada. Proses OLAP data warehouse yang terpisah dengan proses OLTP tidak akan mengganggu aktifitas operasional data call center yang sehari - hari dilakukan oleh petugas Call Center.

\subsection{Implikasi Penelitian \\ 4.8.1. Manaje rial}

Penggunaan data warehouse dalam menyajikan informasi strategik bagi manajemen menjadi sebuah sistem dan prosedural baru dalam organisasi yang membuat pimpinan selaku pengguna sistem informasi ini harus bisa dan terbiasa memanfaatkan fasilitas tersebut.

\subsubsection{Sistem}

Dengan penggunaan data warehouse diharapkan seluruh data yang tidak konsisten akibat sistem informasi call center yang belum sempurna atau kesalahan operator call center saat melakukan entry data ke dalam aplikasi call center dapat diidentifikasi dengan cepat dan diperbaiki, sehingga akan memudahkan proses Extract, Transform and Loading dari data sumber ke data warehouse dan menyederhanakan proses pembuatan pelaporan dan analisis.

\subsubsection{Pene litian Lanjutan}

Hasil penelitian ini juga dapat digunakan sebagai bahan referensi untuk penelitian selanjutnya, seperti penerapan data mining yang dapat dimanfaatkan untuk mencari pola karakteristik dari keperluan mahasiswa, dosen, cabang atau pihak umum menelpon Call Center, serta 
evaluasi keberhasilan suatu pelayan akademik dan pembuatan prediksi permasalahan apa di bidang pelayanan akademik ke depan yang harus segera ditangani dengan baik.

\section{PENUTUP}

\subsection{Kesimpulan}

Berdasarkan hasil penelitian yang telah dilakukan, maka dapat disimpulkan bahwa pengembangan model data warehouse pada Call Center Bina Sarana Informatika telah mampu melakukan ekstraksi data operasional dari sistem informasi call center menjadi ringkasan informasi strategis yang berguna bagi manajemen Bina Sarana Informatika sebagai informasi penunjang dalam melakukan analisa, evaluasi, perencanaan dan pengambilan keputusan di bidang pelayanan akademik.

Penggunaan data warehouse memberikan kemandirian dan kemudahan bagi manajemen dalam memilih bentuk laporan yang diinginkan sesuai informasi yang tersedia. Informasi data warehouse dapat disajikan dengan berbagai dimensi sesuai kebutuhan, karena data warehouse mempunyai kemampuan untuk roll up dan drill down, mampu melakukan query dengan cepat, dan mampu menampilkan data dengan baik dalam bentuk tabular maupun grafik. Dengan tersedianya data warehouse, manajemen dapat memperoleh informasi yang memungkinkan untuk melakukan analisis lebih jauh terhadap subjek - subjek tertentu yang dikehendaki dalam waktu yang lebih cepat.

\subsection{Saran}

Beberapa saran yang perlu dikemukakan untuk pengembangan selanjutnya, antara lain :

1. Perlu adanya regulasi dalam menggunakan telpon di internal BSI Pusat agar semua yang keluar harus melalui Call Center, sehingga data aktifitas telpon keluar dapat direkam ke dalam database operasional secara maksimal oleh petugas Call Center.
2. Penyempurnaan sistem pada pengolahan data operasional, terutama penyempurnaan desain database dan validasi data yang masuk pada aplikasi oprasional Call Center, akan sangat membantu proses ETL dari database sumber ke database data warehouse.

3. Hendaknya data yang masuk ke dalam database operasional perlu diperhatikan oleh petugas Call Center, agar kegiatan cleansing dan perbaikan data pada proses ETL tidak mengalami banyak kesulitan dan terhindar dari inkonsistensi data.

4. Dalam pemilihan tools dan pembangunan infrastruktur jaringan yang akan digunakan untuk merancang data warehouse harus ditentukan dengan baik agar dapat mempermudah proses perancangan maupun pengoperasian data warehouse call center.

5. Perlunya dibuatkan SOP bagi pimpinan sebagai panduan dalam mengoperasikan data warehouse agar tidak terjadinya penyimpangan terhadap informasi yang terjadi pada data warehouse, sehingga manajemen mendapatkan manfaat yang maksimal dari penerapan data warehouse untuk menyajikan informasi startegik.

6. Penelitian selanjutnya diharapkan agar proses penyajian informasi dari data warehouse dapat dilakukan secara online via internet dengan tampilan laporan yang lebih baik, dari sisi tabel rekapitulasi maupun grafik.

7. Penelitian ke depan juga diharapkan sampai pada penerapan data mining yang dapat dimanfaatkan untuk mencari pola karakteristik dari keperluan mahasiswa, dosen, cabang atau pihak umum menelpon Call Center, serta evaluasi keberhasilan suatu pelayan akademik dan pembuatan prediksi permasalahan apa di bidang pelayanan akademik ke depan yang harus segera ditangani dengan baik. 


\section{REFERENSI}

Azimah, Ariana \& Sucahyo, Yudho G. (2007). Penggunaan Data Warehouse dan Data Mining Untuk Data Akademik Sebuah Studi Kasus Pada Universitas Nasional. Jurnal Sistem Informasi MTI UI Vol.3-No.2 Oktober 2007.

http://repository.ui.ac.id/contents/ koleksi/11/22.pdf

Darmawikarta, Djoni (2003). Mengenal Data Warehouse, Tip \& Trik ilmukomputer.com.

Darudiato, Suparto. (2010). Perancangan Data Warehouse Penjualan Untuk Mendukung Kebutuhan Informasi Eksekutif Cemerlang Skin Care. [OnLine].

http://repository.upnyk.ac.id/36/1/ E-

43_PERANCANGAN_DATA_ WAREHOUSE_PENJUALAN_ UNTUK_MENDUKUNG_KEB UTUHAN__INFORMASI_EKSE KUTIF_CEMERLANG.pdf

Faristin, Hanny. (2005). Perancangan data warehouse untuk kegiatan akademik di Universitas Indonesia. Fakultas Ilmu Komputer. Universitas Indonesia.

Gustiarahman, Irfan. (2006). Data Warehouse. April, 28, 2011. http://myhut.org/public/datawareh ouse.doc.

Langit, Lynn. (2007). Foundations of SQL Server 2005 Business Intelligence. New York: Apress.

Mallach, Efrem. G. (2000). Decision Support and Data Warehouse Systems. New York: McGrawHill.

Nugroho, Adi. (2004). Konsep Pengembangan Sistem Basis Data. Bandung: Penerbit Informatika.
Ponniah, Paulraj (2001). Data Warehousing Fundamentals A Comprehensive Guide For IT Proffesionals. New York: WileyInterscience.

Puspitasari, Diah. (2010). Perancangan Data Warehouse Bidang Akademik Studi Kasus Kampus Akademi Bina Sarana Informatika. Tesis. Jakarta. Program Pascasarjana Magister Ilmu Komputer STMIK Nusa Mandiri.

Supriatna, Adi. (2011). Perancangan Data Warehouse Perpustakaan dengan Kimball Nine-Step Methodology : Studi Kasus Perpustakaan Bina Sarana Informatika. Tesis. Jakarta. Program Pascasarjana Magister Ilmu Komputer STMIK Nusa Mandiri. 